\title{
Tentative investigations on surface hoar in mountain forests
}

\author{
Peter Höller \\ Institute for Avalanche Research, Hofburg-Rennweg 1, A-6020 Innsbruck, Austria
}

\begin{abstract}
This paper deals with air temperature, net-radiation and relativehumidity measurements which we performed in Austria in different zones of mountain forests in recent years. Our aim using such measurements was to approximate the general conditions for the formation of surface-hoar layers in low-density forest stands near the timber line. These layers are a necessary condition for snow-slab release and avalanche formation.

Our investigations showed that the total radiation balance was negative but less negative in a forest with a close canopy (on clear nights about -30 to $-40 \mathrm{~W} \mathrm{~m}^{-2}$ ) than within a small clearing $(6 \mathrm{~m}$ by $6 \mathrm{~m})$. Moreover, the total radiation balance within the forest clearing was almost the same as that in an open field. There we measured -60 to $-80 \mathrm{~W} \mathrm{~m}^{-2}$ on clear nights. Approximations of surface temperature $\left(t_{\mathrm{s}}\right)$ showed that $t_{\mathrm{s}}$ was below the dewpoint $\left(t_{\mathrm{E}}\right)$ in an open field but did not reach $t_{\mathrm{E}}$ in the forest; moreover, $t_{\mathrm{s}}$ was very close to $t_{\mathrm{E}}$ within the forest clearing. Water-vapor flux was positive only in open terrain (i.e. condensation between $0.1 \times 10^{-6}$ and $0.9 \times 10^{-6} \mathrm{~kg} \mathrm{~m}^{-2} \mathrm{~s}^{-1}$ ) and evaporation occurred within the clearing and in the forest.
\end{abstract}

\section{INTRODUCTION}

Surface hoar is one of the commonest weak layers within the snowpack and is responsible for avalanche formation and snow-slab release. Many researchers have studied the conditions for surface-hoar growth (Colbeck, 1988; Hachikubo and others, 1994; Hachikubo and Akitaya, 1997a, b; Lang and others, 1985). For example, Colbeck (1988) showed that surface-hoar growth is not possible during calm conditions. Hachikubo and Akitaya (1997a, b) found that the condensation rate is high when the wind speed is from 2 to $3 \mathrm{~m} \mathrm{~s}^{-1}$ at a height of $1 \mathrm{~m}$.

Recent investigations by Bader and Salm (1990) have shown that the presence of an expanded weak layer is a necessary condition for the formation of slab avalanches. In a previous paper, Föhn (1993) explained that, in an Alpine climate, $80 \%$ of all the weak layers consist of either surface hoar, faceted particles or depth hoar. In the past, it has been assumed that the formation of surface hoar was possible only in open fields but our observations in recent years have shown that it can also occur in forest stands. After analysing our avalanche statistics, we have established that back-country skiers have triggered avalanches in low-density forests, particularly as a consequence of covered surface hoar.

It seemed that larch stands (low-density stands) with a low canopy density and forests with a high number of gaps and clearings are prone to slab avalanches. These and other observations have culminated in a project which was initiated by our institute at the end of the 1980s. This paper shows some preliminary results, especially measurements on air temperature, radiation balance and wind speed at two different forest sites and in open terrain. In addition, some simple calculations on snow-surface temperature have also been included. The aim of the study was to discover whether conditions for surface-hoar growth could also exist within larch stands with a low-canopy density and within forest clearings.

\section{STUDY AREA AND METHODS OF MEASUREMENTS}

The study field was about $35 \mathrm{~km}$ from Innsbruck (in Stubai valley) located in and beside a larch stand near the timber line at about $1900 \mathrm{~m}$ a.s.l. Three different measuring zones (open field (1), clearing (2) and dense forest (3)) were selected. Zone 1 was outside the forest and not influenced by the forest canopy; measuring zone 2 was a forest clearing with a diameter of approximately $6 \mathrm{~m} \times 6 \mathrm{~m}$ (only $20 \%$ of the sky was covered by trees); position (3) was in the forest with touching crowns (about $80 \%$ of the sky was covered by forest canopy).

The monitoring program was restricted to the following parameters which were recorded at all sites: air temperature, relative humidity, wind speed and total radiation balance. Air temperature was measured with platinum-resistance sensors the relative humidity with capacitive probes (VAISALA). The temperature and humidity sensors were placed within standardized radiation shields. Three-cup anemometers were used to measure the wind speed. Radiation balance was measured by net pyrradiometers manufactured by SCHENK (spectral range $0.3-50 \mu \mathrm{m}$ ). Parameters were measured at a height of $1 \mathrm{~m}$. All data were recorded at intervals of $15 \mathrm{~min}$ and stored on three data loggers.

Additional measurements, registered only at position No. 1 (open field), included snow depth (ultrasonic gauge), snow-temperature profile, snow-surface temperature (infrared thermometer), and incoming and outgoing short- and longwave radiation (star pyranometers and pyrradiometers). Further details regarding the various measurement devices have been published by Höller (1997). 


\section{RESULTS}

The measurements in Figures 1 and 2 show that the air temperature $\left(t_{\text {air }}\right)$ and the relative humidity were similar at all sites. It was interesting to note that $t_{\text {air }}$ in the open field was warmer than in the clearing and also in the forest at night. Although the difference during night-time was small, it was the very opposite of what one would expect (i.e. warmer under the canopy than in open terrain). However, Aulitzky and Turner (1982) have measured air temperatures in clearings and stone-pine stands in the central Alps and found a similar tendency. Of course the results were from a summer period and those values show that we could also expect lower temperatures under a canopy.

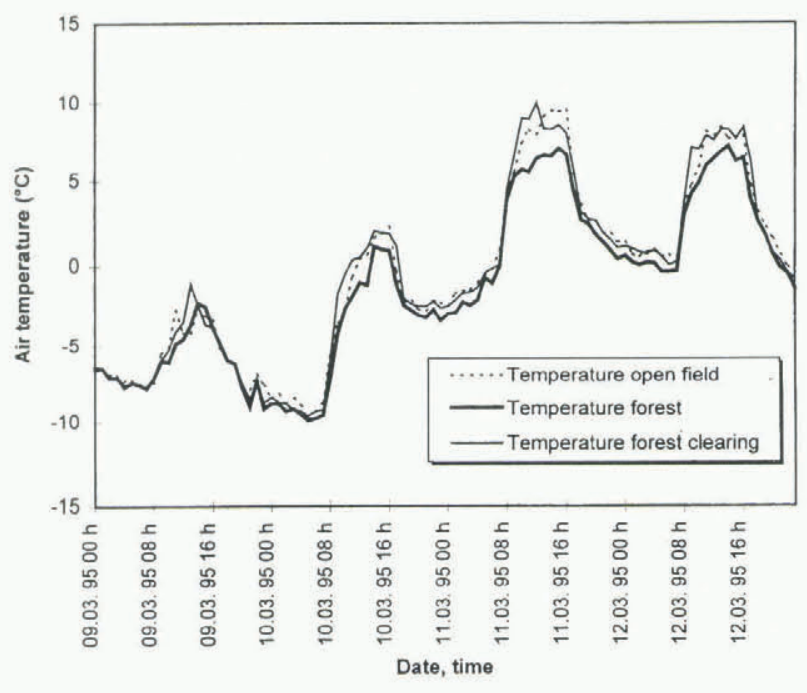

Fig. 1. Measured air temperatures from 9-12 March 1995, in three different zones.

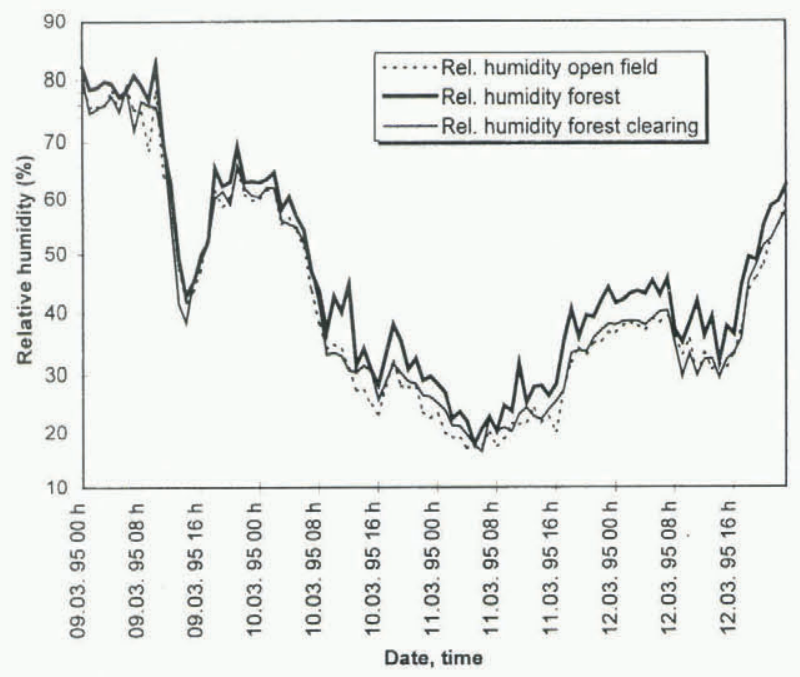

Fig. 2. Measured relative humidity from 9-12 March 1995, in three different zones.

With regard to wind, there was almost no difference between wind speed on the open terrain and in the forest clearing. On the other hand, wind speed in the forest was about two-thirds of that measured in the clearing. Table 1 shows the average monthly wind speed for the different measuring zones (January-March 1995).
Table 1. Average monthly wind speed in selected measuring zones: 1 January-31 March 1995

\begin{tabular}{|c|c|c|c|}
\hline Month & $\begin{array}{c}\text { Open field } \\
\mathrm{ms}^{-1}\end{array}$ & $\begin{array}{l}\text { Measuring zone } \\
\text { Forest clearing } \\
\qquad \mathrm{m} \mathrm{s}^{-1}\end{array}$ & $\begin{array}{l}\text { Forest } \\
\mathrm{m} \mathrm{s}^{-1}\end{array}$ \\
\hline January & 0.8 & 0.8 & 0.5 \\
\hline February & 0.8 & 0.8 & 0.5 \\
\hline March & 0.8 & 0.7 & 0.4 \\
\hline
\end{tabular}

Radiation balance depended greatly on canopy density; it was highest in the forest, whereas measurements within the clearing were almost the same as in the open field. As an example, the period between 9 and 12 March 1995 is discussed. Temperature and relative humidity are shown in Figures 1 and 2, and the total radiation balance in Figure 3. During this period, clear-sky conditions prevailed. It was established that the total radiation balance during clear nights (7 p.m. to 6 a.m.) was always higher (i.e. less negative) in the forest than within the clearing or in the open field. We measured about $-30 \mathrm{~W} \mathrm{~m}^{-2}$ in the forest and $-60 \mathrm{Wm}^{-2}$ within the clearing and the open field. The incoming longwave radiation during clear nights on the open field was $190 \mathrm{~W} \mathrm{~m}^{-2}$. Detailed approximations focused on the time between 7 p.m. and 6 a.m., the night between 9 and 10 March 1995, because it was assumed that the conditions for surface hoar growth were more likely to be found on clear nights. As mentioned above, detailed measurements of incoming and outgoing radiation were recorded only at site 1 (open field). For all other measuring zones, we approximated the incoming longwave radiation (spectral range from about $3-50 \mu \mathrm{m}$ with a peak near $10 \mu \mathrm{m}$ ) using the following assumptions:

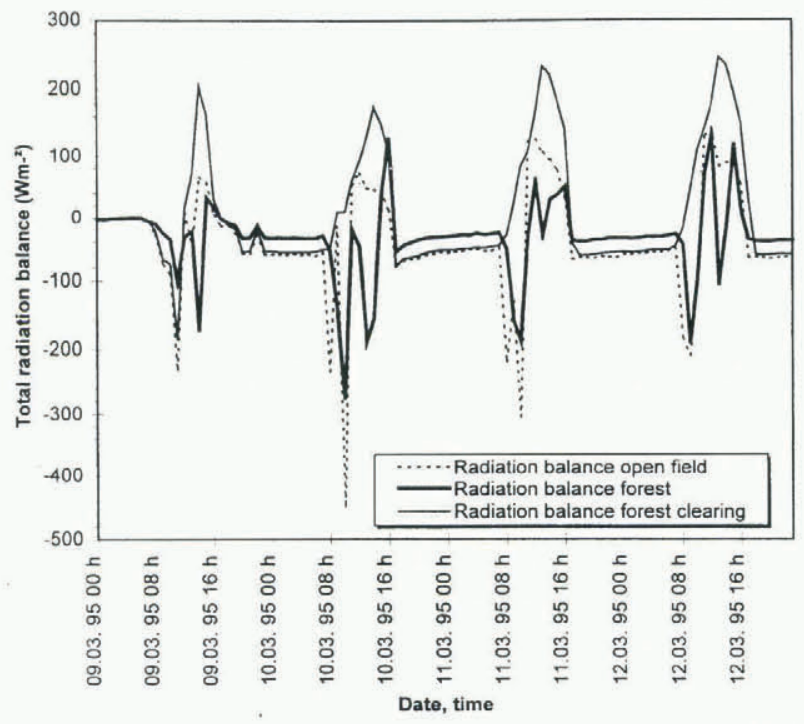

\section{Fig. 3. Total radiation balance from 9-12 March 1995, in three different zones.}

For the forest we assumed that incoming longwave radiation, mainly from the trees, would be about 1.3 times higher than incoming longwave radiation from the clear sky, because the clear sky has an emissivity of about 0.7 and the emissivity of trees is about 0.9 (Sellers, 1965; Gubler and Rychetnik, 1991; Bader and Weilenmann, 1992). Thus, the in- 
cident longwave radiation in the forest was estimated to be about $240-250 \mathrm{~W} \mathrm{~m}^{-2}$. For the forest clearing, we adopted an idea put forward by Bader and Weilenmann (1992). We assumed that about $20 \%$ of the open sky was covered by trees. Assuming that $t_{\text {tree }}$ is equal to $t_{\text {air }}$ (Bader and Weilenmann, 1992), we found that the incoming longwave radiation was approximately $200 \mathrm{~W} \mathrm{~m}^{-2}$ for site 2 (forest clearing).

As mentioned above, these investigations were concentrated particularly on the night period, between 7 p.m. and 6 a.m., which meant that it is possible to approximate outgoing longwave radiation with the following equation:

$$
I=I \downarrow-I \uparrow
$$

where $I$ is the longwave radiation balance, $I \downarrow$ is the incident longwave radiation and $I \uparrow$ is the outgoing longwave radiation (all values in $\mathrm{W} \mathrm{m}^{-2}$ ).

Surface temperature of snow during the night was subsequently approximated by the Stefan-Boltzmann law:

$$
I \uparrow=\varepsilon_{\mathrm{s}} \sigma \mathrm{T}_{\mathrm{s}}^{4}
$$

where $I \uparrow$ is the outgoing longwave radiation (inW $\mathrm{m}^{-2}$ ), $\varepsilon_{\mathrm{s}}$ is the emissivity of snow (0.9), $\sigma$ is the Stefan-Boltzmann constant and $T_{\mathrm{s}}$ is the surface temperature of snow (in $\mathrm{K}$ ).

As shown in Figure 4, the calculated surface temperature was in the later part of the night between $-12^{\circ}$ and $-15^{\circ} \mathrm{C}$ on site 1 (open field) and between $-11^{\circ}$ and $-14^{\circ} \mathrm{C}$ on site 2 (forest clearing).

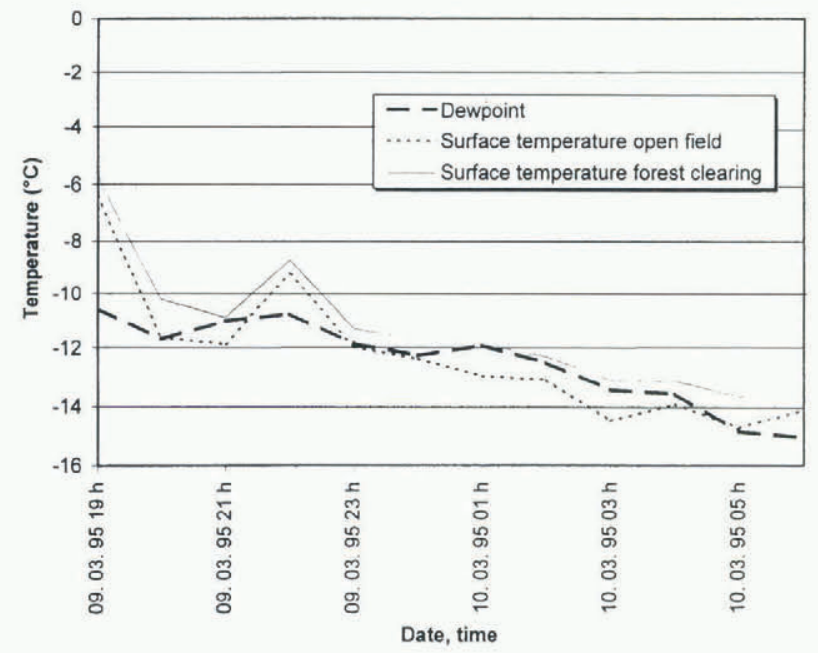

Fig. 4. Approximated dewpoints and surface temperatures on open terrain and within the forest clearing (9-10 March 1995).

By using the air temperature and relative humidity measurements, two dewpoint graphs for the night of 9-10 March were plotted (cf. Figures 4 and 5). In Figure 4, the open terrain and the forest clearing are presented, because the air temperature and relative humidity were very similar at those sites. Figure 5 shows the surface temperature $\left(t_{\mathrm{s}}\right)$ and the dewpoint temperature $\left(t_{\mathrm{E}}\right)$ for the forest stand. It is apparent that the surface temperature of snow $\left(t_{\mathrm{s}}\right)$ was below the dewpoint at site 1 (open field) but did not reach the dewpoint temperature $\left(t_{\mathrm{E}}\right)$ in the forest; moreover, we established that $t_{\mathrm{s}}$ was very close to $t_{\mathrm{E}}$ within the clearing. On the other hand, it was found that $t_{\mathrm{s}}$ in the forest (Fig. 5) showed significantly higher values than at sites 1 and 2 (Fig. 5).

To discover more details on surface-hoar growth, we also calculated the water-vapor flux. We used a method described by Hachikubo and Akitaya (1997a). They found that the water-vapor condensation rate of surface hoar can be estimated roughly from the atmospheric pressure, the air temperature, relative humidity, surface temperature and wind speed. They used a bulk method for calculating water-vapor flux $\left(E\right.$ in $\left.\mathrm{kg} \mathrm{m}^{-2} \mathrm{~s}^{-1}\right)$ :

$$
E=(0.622 / p) C_{\mathrm{e}} \rho u_{z} \Delta P
$$

where $p$ is the atmospheric pressure (in $\mathrm{Pa}$ ), $C_{\mathrm{e}}$ is the bulktransfer coefficient of water vapor, $\rho$ is the density of air (in $\mathrm{kg} \mathrm{m}^{-3}$ ), $u_{\mathrm{z}}$ is the wind speed (in $\mathrm{m} \mathrm{s}^{-1}$ ) at height $z$ (for our assumptions we used the wind-speed measurements taken at a height of $1 \mathrm{~m}$ ) and $\Delta P$ is the difference of water-vapor pressure between the height of $1 \mathrm{~m}$ (air-temperature measurement) and the snow surface (in $\mathrm{Pa}$ ).

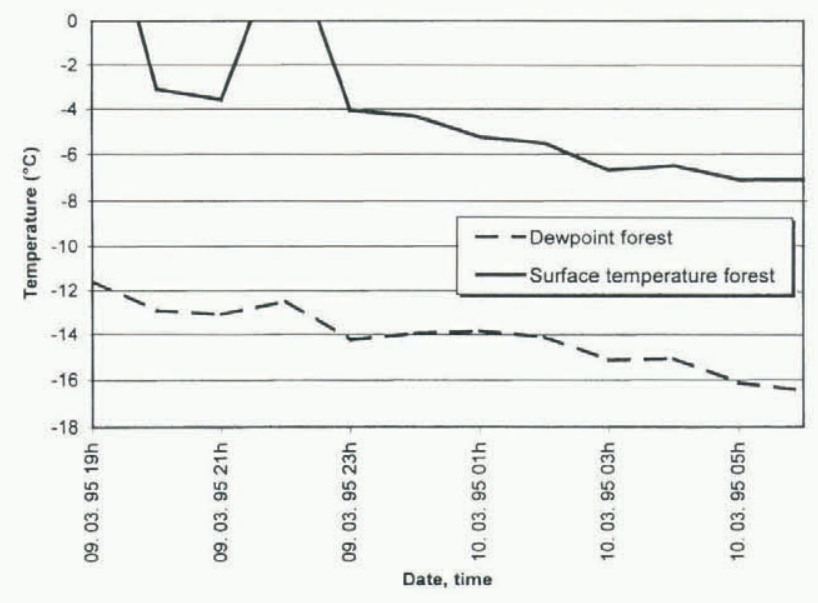

\section{Fig. 5. Approximated dewpoint and surface temperature in the forest stand (9-10 March 1995).}

According to Hachikubo and Akitaya (1997a), a mean value of $2.9 \times 10^{-3}$ at $1 \mathrm{~m}$ height was taken for $C_{\mathrm{e}}$. Watervapor pressure was calculated by taking into account relative humidity and air temperature. Vapor pressure at the snow surface was calculated from $t_{\mathrm{s}}$, assuming saturation with respect to ice.

Table 2 shows the condensation, respectively the evaporation rate during the night of 9 and 10 March 1995, for the different measuring zones.

\begin{tabular}{|c|c|c|c|}
\hline Time & $\begin{array}{c}\text { Open field } \\
10^{-6} \mathrm{~kg} \mathrm{~m}^{-2} \mathrm{~s}^{-1}\end{array}$ & $\begin{array}{l}\text { Measuring zone } \\
\text { Forest clearing } \\
10^{6} \mathrm{~kg} \mathrm{~m}^{2} \mathrm{~s}\end{array}$ & $\begin{array}{c}\text { Forest } \\
10^{6} \mathrm{~kg} \mathrm{~m}^{2} \mathrm{~s}^{1}\end{array}$ \\
\hline $19.00-20.00$ & -0.1 & -1.7 & -2.0 \\
\hline $20.00-21.00$ & +0.7 & -0.1 & -2.0 \\
\hline $21.00-22.00$ & -1.1 & -1.4 & -3.9 \\
\hline $22.00-23.00$ & +0.1 & -0.4 & -2.8 \\
\hline $23.00-00.00$ & +0.1 & -0.4 & -1.9 \\
\hline $00.00-01.00$ & +0.9 & +0.1 & -2.7 \\
\hline $01.00-02.00$ & +0.6 & -0.2 & -1.7 \\
\hline $02.00-03.00$ & +0.6 & -0.1 & -1.1 \\
\hline $03.00-04.00$ & +0.2 & -0.5 & -2.1 \\
\hline $04.00-05.00$ & -0.1 & -0.8 & -2.3 \\
\hline $05.00-06.00$ & -0.5 & -0.5 & -2.6 \\
\hline
\end{tabular}

Table 2. Condensation rate $(+)$, respectively evaporation rate (-) $\times 10^{-6} \mathrm{~kg} \mathrm{~m}^{-2} \mathrm{~s}^{-1}$ during the night of 9-10 March 1995 


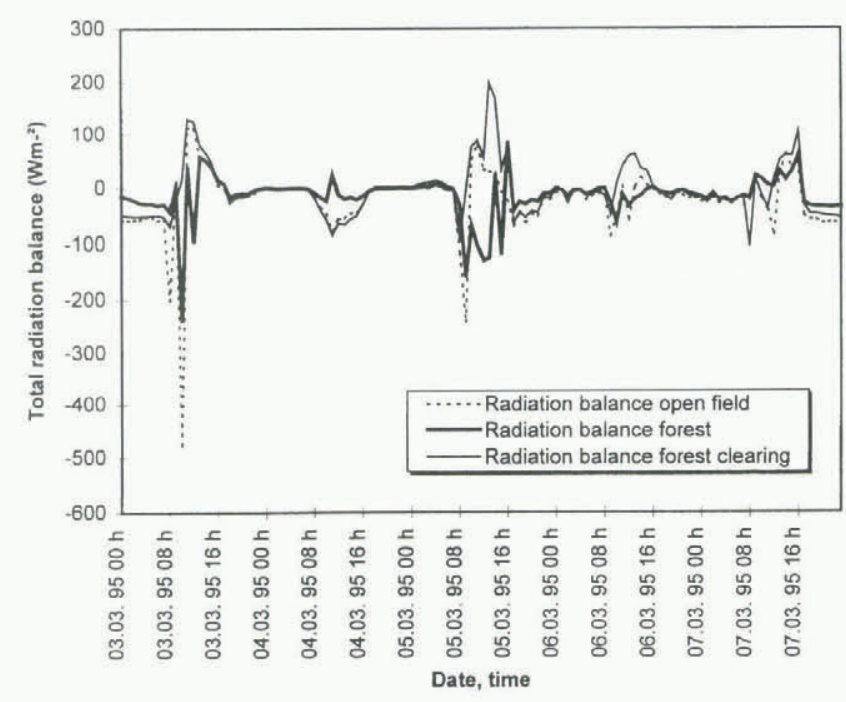

Fig. 6. Total radiation balance from 3 to 7 March 1995 (overcast sky).

The results show that vapor flux is mostly positive (downward) in the open terrain (condensation rates between +0.1 and $+0.9 \times 10^{-6} \mathrm{~kg} \mathrm{~m}^{-2} \mathrm{~s}^{-1}$ ). In the clearing, evaporation was predominant, although the calculated values were relatively small. The vapor flux was significantly negative in the forest (with values between -1.0 and $-3.0 \times 10^{-6} \mathrm{~kg} \mathrm{~m}^{-2} \mathrm{~s}^{-1}$ ). This indicates that under the given meteorological conditions surface hoar might be formed in the open field but not within the clearing and in the forest.

Taking into account that relative humidity was rather small $(60-65 \%)$, it could be assumed that increasing humidity would lead to higher condensation rates in the open terrain as well as in the clearing. At the forest clearing, the water-vapor pressure differences $(\Delta P)$ were insignificantly below 0 , therefore large values of relative humidity would also be sufficient to produce condensation within the forest clearing. In the dense forest, $\Delta P$ was significantly negative, so that condensation rates and surface-hoar growth could not be expected. Only on clear and very humid nights (relative humidity $90 \%$ or more) could $\Delta P$ increase up to 0 or more. As measuring position 3 (forest) was situated in a larch stand with a canopy density of less than $80 \%$, this possibility could not be excluded.

Last but not least, it must be mentioned that on overcast nights, for example, during the period 3-7 March 1995 ( see Fig. 6), the total radiation balance was very similar at all sites (about $0 \mathrm{~W} \mathrm{~m}^{-2}$ ), which meant that surface temperatures did not decrease appreciably below the air temperature during those nights.

\section{GONGLUSION}

To summarize our investigations, we can say that during the observed clear nights air-temperature and relative-humidity values were similar in the different measuring zones. However, the total radiation balance on clear nights depended on the forest canopy. The approximated surface temperatures were more or less similar and cold on open terrain and in the forest clearing (the minimum temperature was approximately $-15^{\circ} \mathrm{C}$ ) but were relatively warm in the forest. Only the surface temperatures in the open field fell clearly below the dewpoint, while in the forest clearing the surface temperature reached the dewpoint only in few cases.

Approximations of condensation rates show that vapor flux is mainly positive towards the snow surface in the open terrain. Evaporation was predominant both in the forest and in the forest clearing but these values were relatively small. Thus, we might assume that slightly larger values of relative humidity would sometimes yield condensation also in the forest clearing.

In conclusion, we can say that conditions for surfacehoar growth are possible mainly in open terrain. If the relative humidity is higher than approximately $75 \%$, there is also some possibility for hoar growth in the forest clearings. In the forest itself, at least in a larch stand with a canopy density of $80 \%$, the surface-hoar growth seems to be impossible except when the relative humidity is very large, say more than $90 \%$ and winds are moderate (cf. Hachikubo and Akitaya, 1997a).

As the initial intention of these preliminary investigations was to sound out tentatively whether the conditions for surface-hoar growth could exist in forest clearings we have not yet completed any tests to see whether surface hoar has really formed. The preliminary results obtained have encouraged us to carry out further investigations on this important issue.

\section{REFERENCES}

Aulitzky, H. and H. Turner. 1982. Bioklimatische Grundlagen einer standortsgemässen Bewirtschaftung des subalpinen Lärchen-Arvenwaldes. Eidg. Anst. Forstl.Versuchswes, Mitt., 58(4), 327-580.

Bader, H. -P. and B. Salm. 1990. On the mechanics of snow slab release. Cold Reg. Sci. Technol., 17 (3), 287-300.

Bader, H. -P. and P. Weilenmann. 1992. Modeling temperature distribution, energy and mass flow in a (phase-changing) snowpack. I. Model and case studies. Cold Reg. Sci. Technol., 20(2), 157-181.

Colbeck, S. C. 1988. On the micrometeorology of surface hoar growth on snow in mountainous area. Boundary-Layer Meteorol., 44(1-2), 1-12.

Föhn, P. M. B. 1993. Characteristics of weak snow layers or interfaces. In Armstrong, R., ed. ISSW 92. A Merging of Theory and Practice. International Snow Science Workshop, 4-8 October 1992, Breckenridge, Colorado. Proceedings. Denver, CO, Avalanche Information Center, 160-170.

Gubler, H. and J. Rychetnik. 1991. Effects of forests near the timberline on avalanche formation. International Association of Hydrological Sciences Publication 205 (Symposium at Vienna 1991 - Snow, Hydrology and Forests in High Alpine Areas), $19-38$.

Hachikubo, A. and E. Akitaya. 1997a. The effect of wind on surface hoar growth on snow. 7. Geophys. Res., 102(D4), 4367-4373.

Hachikubo, A. and E. Akitaya. 1997b. Observation and numerical experiment concerning the wind effect on surface hoar condensation. In International Conference on Avalanches and Related Subjects, September 2-6, 1996, Kirovsk, Russia. Proceedings. Kirovsk, Murmansk, Production Association "Apatit", 72-76.

Hachikubo, A., T. Fukuzawa and E. Akitaya. 1994. Formation rate of surface hoar crystals under various wind velocities. In ISSW'94. International Snow Science Workshop, 30 October-3. November 1994, Snowbird, Utah. Proceedings. Snowbird, UT, P.O. Box 49, 132-137.

Höller, P. 1997. Experience with snow measurement devices in avalanche research. In Third International Conference on Snow Engineering, May 26-31, 1996, Sendai, Japan. Proceedings. Rotterdam, Balkema, 101-104.

Lang, R. L., B. R. Leo and R. L. Brown. 1985. Observations on the growth process and strength characteristics of surface hoar. In ISSW84. International Snow Science Workshop, $24-27$ October 1984, Aspen, Colorado. Proceedings. Aspen, CO., ISSW Workshop Committee, 188-195.

Sellers, W. D. 1965. Physical climatology. Chicago and London, University of Chicago Press. 